\title{
A new method for protecting the structure's concrete elements from the various effects of moisture.
}

\author{
Saleh Kamel Haidar * \\ Mohamed Ali Barakat ** \\ Hesham Sameh Hossien ***
}

\section{ABSTRACT.}

The standard and the maintenance level of buildings in any country are invariably directly related to the strength of its economy. Growing countries are regularly facing the problem of maintaining buildings as its cost is considerably high.

Several approaches were innovated to facilitate both the methods and the costs of maintenance. Low cost, simple and minimum maintenance procedure is the best approach that suite the growing countries conditions. Protecting fresh structure's elements may be one of the solutions that decrease and minimize the maintenance cost.

As the local construction systems in Egypt depend mainly on concrete elements such as foundations, columns and slabs (skeleton construction system), so protecting these elements can be considered as a major step toward reducing the maintenance cost.

The main expected risk that is threatening the concrete elements is moisture. Moisture is the principal agent of deterioration and is probably also the agent with the greatest influence on the properties of materials. It can exist in the form of solid (snow and hailstones), liquid (rain) or vapour. Also moisture is a prerequisite for physical, chemical and biological reactions to take place [R1]. Although the percentage occupied by wet areas is usually not more than $10 \%$ of a buildings gross floor area, the annual maintenance cost for wet area can range from $35 \%$ to $50 \%$ of the total maintenance cost of a building [R2].

This paper examines a new method based on using the normal polystyrene as a protective envelope to protect the different concrete elements of structures from being affected by harmful effects of moisture.

KEY WORDS.

Building technology, Waterproofing, Concrete protection.

\section{INTRODUCTION.}

Concrete is one of the most widely used construction materials worldwide. This is due to its simplicity, superior properties and low cost. However, there are a few major flaws in the properties of concrete such as the low tensile strength and the porosities. The occurrence of internal pores is owed to the nature of concrete itself. Hardened concrete is a direct product of the hydration reaction processes which involve the reaction between water and cement particles. In all cases, the leftover water in concrete, once dried out, will turn into pores (mostly capillary pores) in various sizes. 
These pores are either connected to each other directly or through the gel pores. The existing of high volume of pores put concrete in the risk of being penetrated by water, gas or other chemical substances which could be harmful to concrete and slowly, lead to the deterioration of structures.

Often, the deterioration process starts with the occurrence of the surface cracks (due to the poor tensile strength, shrinkage, etc.) and then follows by the migration of the gases or liquids into the inner-concrete (through the surface cracks and the pores). Some unknown gases or chemical substances can react with concrete and cause the lost integrity and properties. Example of such reactions include the carbonation reaction between carbon dioxide gas and calcium hydroxide (cause the leaching of bicarbonate) which makes concrete surface become porous, decay and permeable, or the chloride induced-corrosion in rebar which causes by the loss of protective film around the rebar due to the decreasing $\mathrm{pH}$ value [R3].

In order to reduce the risk of concrete from being deteriorated, the permeability resistance of concrete must be improved. This paper spotlights the role of using new protective envelope to protect the concrete from being attacked by water (moisture).

\section{METHODS OF PROTECTING CONCRETE.}

There are several techniques to protect concrete from being exposed to harmful substances and to improve its permeability. These techniques can take the following approaches [R4, R5]:

\section{a) Reducing the total volumes of pores.}

Supplementary material such as silica fume or fly ash is very well-known to effectively reduce the total volume of pores.

b) Reducing the volume of larger sized pores (permeable pores).

Extra- or superfine aggregate can be used as a filling material to fill pores in concrete. Also, partially or fully adding/mixing polymer into concrete (so called concrete polymer composite) is another way to improve the permeability resistance of concrete.

c) Creating a protective envelope to prevent various harmful substances from penetrating the outside surface.

Epoxies, bitumen and other materials can be used as a protective envelope to resist water from penetrating concrete.

Each of the previous approaches has various techniques and methods that are capable of offering protection to concrete. The purpose of the study in this paper will concentrate on a new technique on the third approach, by creating a protective envelope from a new material that will prevent various harmful substances specially water, in its various states, from penetrating the outside surface of concrete. 


\section{INCONVENIENCES IN USING THE CURRENT PROTECTION METHODS.}

The current protection methods of creating an envelope to prevent water from penetrating the outside surfaces of concrete have various forms. Most of these forms validate their role in acceptable values. But despite the advantages of these forms some inconvenient points may figure out [R6], especially in the application techniques of these methods. These points can be summarized as follows:

a) The used material is a complicated material that has to be supplied from a main manufacturer.

b) The need of skilled and well trained labors to apply the used material.

c) Special requirements may have to be taken in consideration during the application method of the material such as bitumen that needs a high temperature to apply its technique.

d) The cost of the technique sometimes may be considerably high.

For that, a new material and a new technique will be presented in this paper that overcomes the previous points, by using on hand materials in simple, easy and safe method to achieve a high protection level to concrete from water.

\section{THE NEW TECHNIQUE.}

The new technique depends on using a solute material its base is the normal polystyrene [R7] and a solvent in a specific ratio. The outcome solution will be applied over the concrete surface that after drying will form a protective envelope against water in its various states.

\section{EXPERIMENTAL SETTING.}

The concrete cubes used in the experiment consisted of Portland cement, sand, aggregate and water. The mix proportions of all concrete was set at $1: 2: 4: 0.5$ (cement : sand : aggregate : water).

The concrete was mixed using a pan type mixer, placed in cubic $200 \times 200$ x $120 \mathrm{~mm}$ metal moulds in three layers and each layer was roughly compacted with steel rod. After 24 hours, the specimens were demoulded and subjected to a combined curing of 28 days water +15 days air cure until the date of applying the material.

After applying the protective material, the water penetration test (Din 1048, Fig. 1) [R8 and R9] will be carried out and the cut specimens (Fig. 2) will be observed to asses the water penetration level of each specimen. 


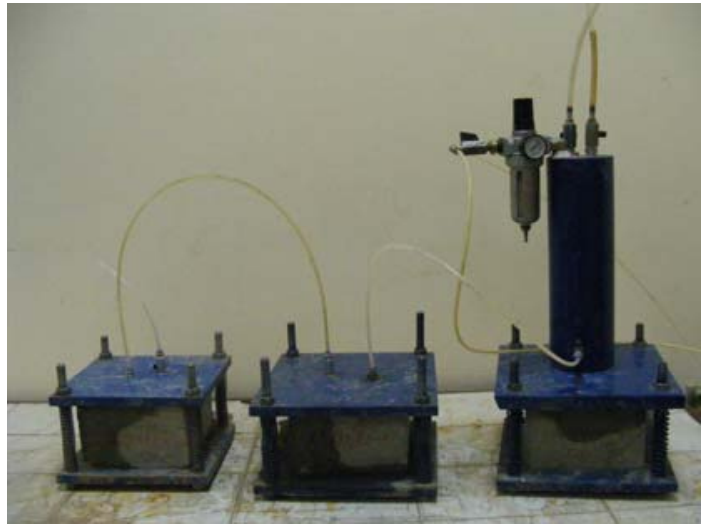

Fig. 1 : The water penetration test (Din 1048).

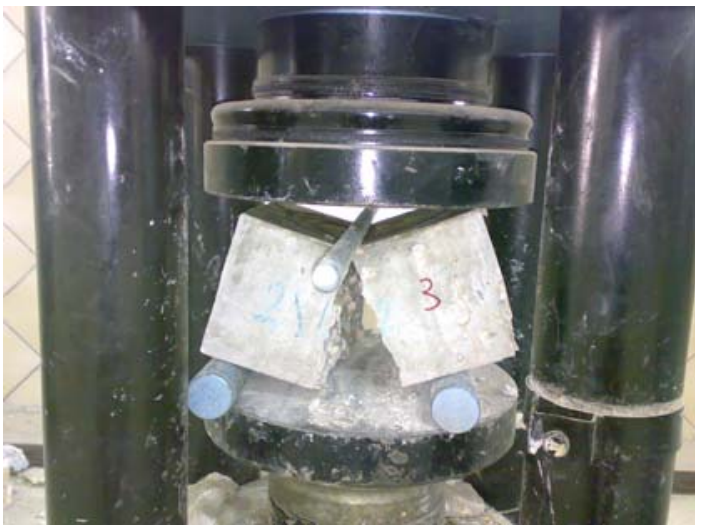

Fig. 2 : Specimen cut process.

\section{THE REFERENCE SCENARIO.}

The reference scenario with which all the tests outputs will be compared, is the water penetration level inside the concrete cubes without applying any type of protection (Fig. 3).
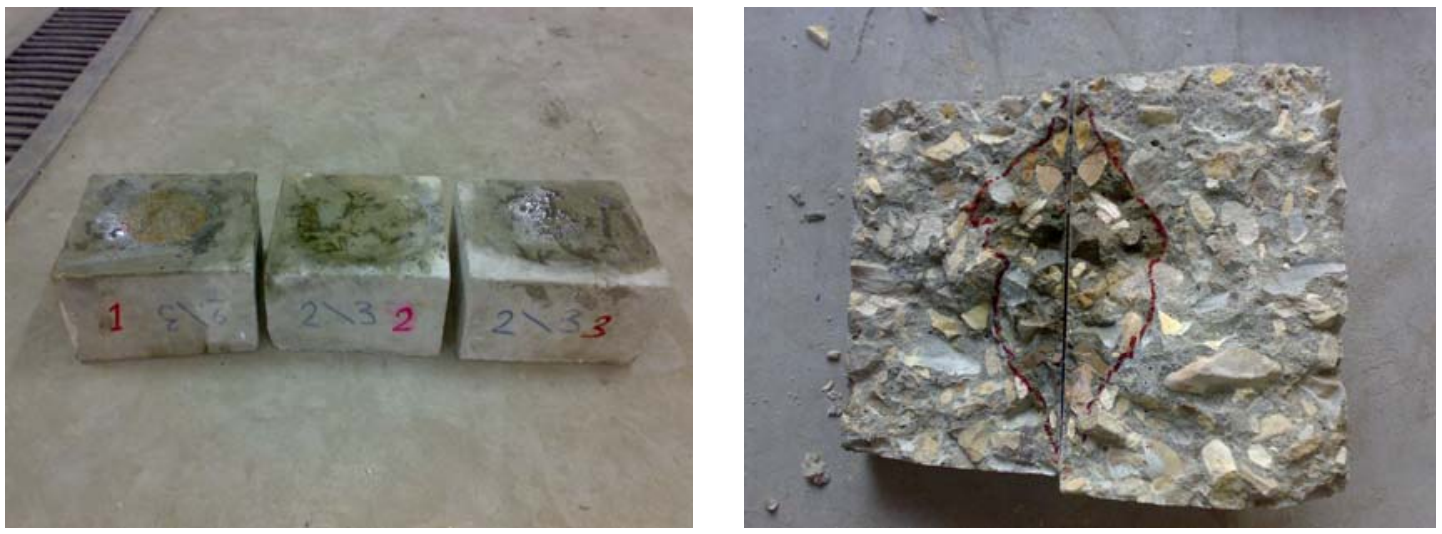

Fig. 3 : The reference scenario.

\section{EXPERIMENTAL PROCEDURE.}

To evaluate the effectiveness of the new technique 30 concrete cubes were prepared. For the reference scenario 3 cubes were set while the examination process is classified into 3 groups each group of cubes was cured by different ratio of the protective solution based on 1.2 and 3 layers (coats).

Table (1) shows the details of the examination process including the number of cubes, the different ratio of the protective solution components, and the number of layers (coats) that are applied to each group of specimens.

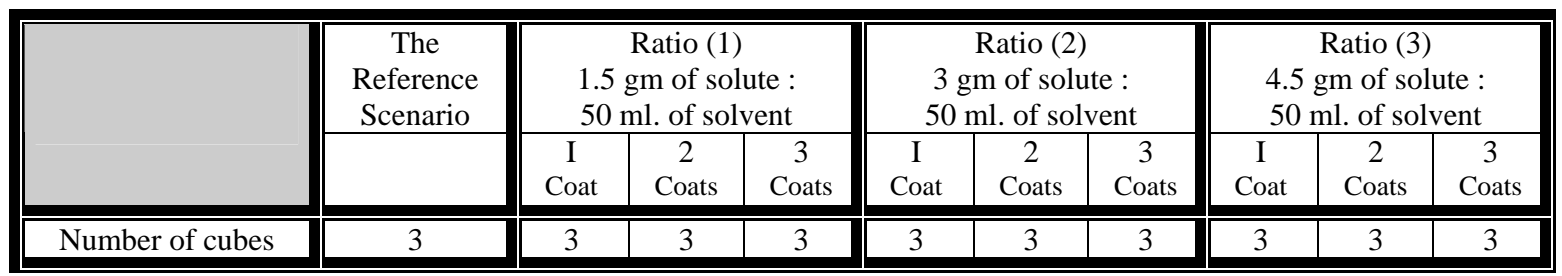

Table (1) : The number of specimens (cubes) in each experimental process. 


\section{WATER PENETRATION RESISTANCE.}

Results from the tests are given in table (2) and Fig. (4). The average penetration depth for the reference scenario was found to be $5.23 \mathrm{~cm}$. while the averages for the specimens covered by the protective solution (Fig. 5) were less till it tends to reaches zero.

It was believed that the polystyrene solution, once properly formed in specific ratio, was able to fill-up the pores at the surface of concrete and seal-up water from penetrating through (Fig. 6).

\begin{tabular}{|c|c|c|c|c|c|c|c|c|c|c|}
\hline & \multirow{2}{*}{$\begin{array}{c}\text { The } \\
\text { Reference } \\
\text { Scenario } \\
\text { No Layers }\end{array}$} & \multicolumn{3}{|c|}{$\begin{array}{c}\text { Ratio (1) } \\
1.5 \text { gm of solute : } \\
50 \text { ml. of solvent }\end{array}$} & \multicolumn{3}{|c|}{$\begin{array}{c}\text { Ratio (2) } \\
3 \text { gm of solute : } \\
50 \text { ml. of solvent } \\
\end{array}$} & \multicolumn{3}{|c|}{$\begin{array}{c}\text { Ratio (3) } \\
4.5 \text { gm of solute : } \\
50 \text { ml. of solvent }\end{array}$} \\
\hline & & $\begin{array}{c}\text { I } \\
\text { Coat }\end{array}$ & $\begin{array}{c}2 \\
\text { Coats }\end{array}$ & $\begin{array}{c}3 \\
\text { Coats }\end{array}$ & $\begin{array}{c}\text { I } \\
\text { Coat }\end{array}$ & $\begin{array}{c}2 \\
\text { Coats }\end{array}$ & $\begin{array}{c}3 \\
\text { Coats }\end{array}$ & $\begin{array}{c}\text { I } \\
\text { Coat }\end{array}$ & $\begin{array}{c}2 \\
\text { Coats }\end{array}$ & $\begin{array}{c}3 \\
\text { Coats }\end{array}$ \\
\hline Cube 1 & 5.3 & 4.9 & 4.6 & 3.8 & 4.6 & 3.8 & 2.5 & 2.6 & 1.5 & 0 \\
\hline Cube 2 & 5.5 & 5 & 4.5 & 3.5 & 4.8 & 3.4 & 2.4 & 2.8 & 0.9 & 0 \\
\hline Cube 3 & 4.9 & 4.8 & 4.8 & 3.6 & 4.5 & 3.3 & 2.7 & 3 & 1 & 0.1 \\
\hline $\begin{array}{c}\text { Average water } \\
\text { penetration depth }(\mathrm{cm} .)\end{array}$ & 5.23 & 4.9 & 4.63 & 3.63 & 4.63 & 3.5 & 2.53 & 2.8 & 1.13 & 0.034 \\
\hline
\end{tabular}

Table (2) : Depths and average depths of water penetrations (cm.).

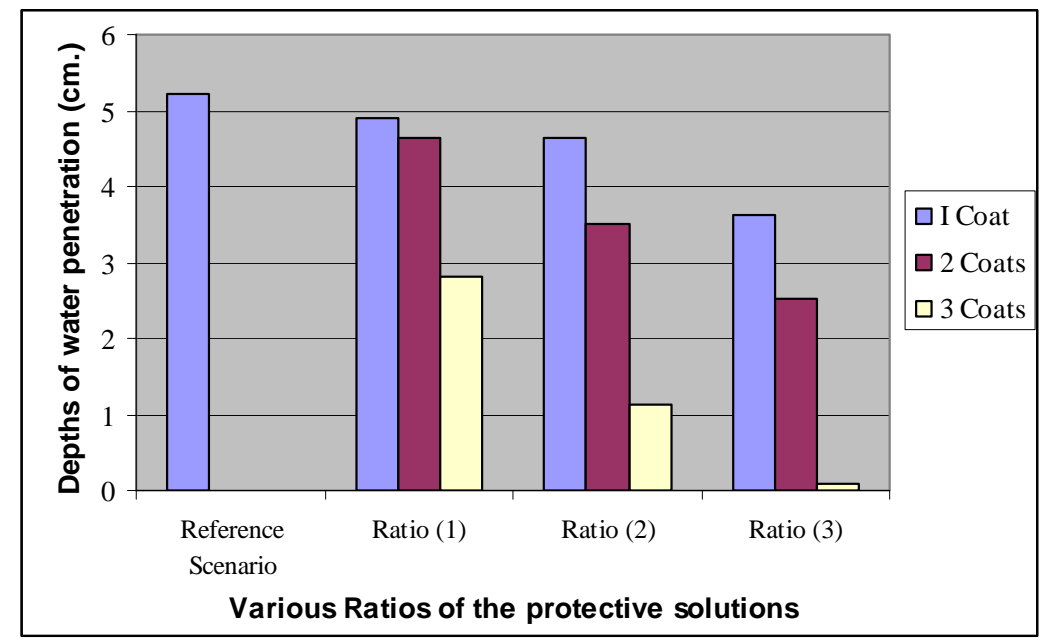

Fig. 4 : The average depths of water penetration.

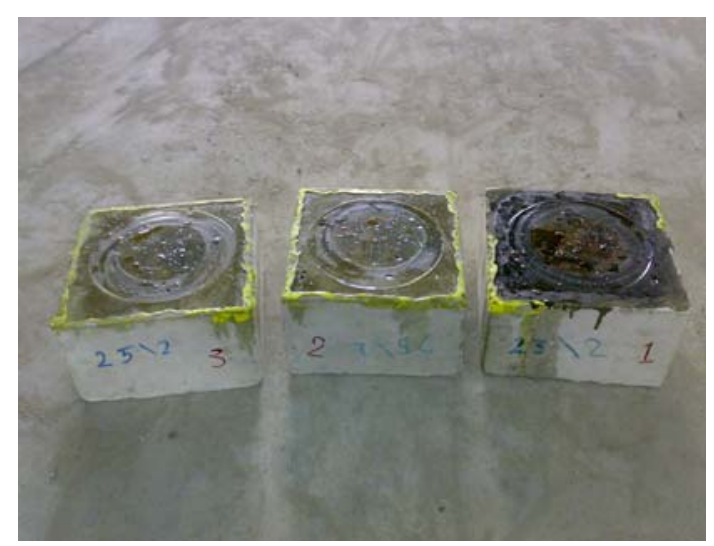

Fig. 5 : Cured specimens before the cutting process.

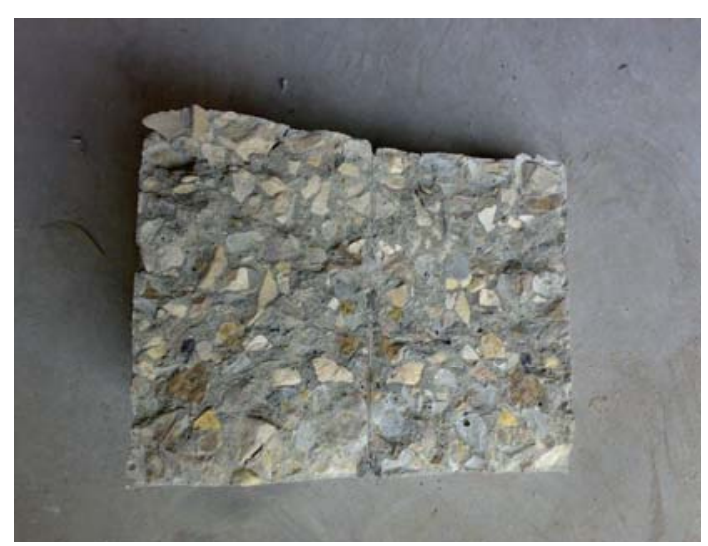

Fig. 6 : 3 coats Cured specimens after the cutting 


\section{CONCLUSIONS.}

1- The resistance to water penetration of concrete could be improved significantly by simply applying a thin protective layer(s) (coat(s)) of a polystyrene based solution at the outer surfaces of concrete elements.

2- The resistance to water penetration of concrete could be achieved significantly by using simple method depending on available materials and no special requirements.

3- The resistance to water penetration of concrete could be accomplished on site without depending on skill or trained labors.

\section{REFERENCES.}

1- Building Maintenance Technology, Lee How Son \& George C. S. Yuen, The Macmillan Press LTD, 1993.

2- Chew M. Y. L., School of design and environment, Construction and building materials 19, ELSEVIER, (2005).

3- ACI Manual of concrete practice, American concrete institute, Farmington hills, USA, 2001.

4- Concrete repair and maintenance, Peter H. Emmons, Galgotia publications pvt. Ltd, 2001.

5- Perkins P.H., Repair, Protection and Waterproofing of Concrete Structures, Third Edition, E \& FN SPON, 2003.

6- Building maintenance and preservation, A guide for design and management, Dwards D. Mills, Butterworths, 1980.

7- Polymers: Chemistry and physics of modern materials, Cowie J. M. G., Chapman and hall, New York, USA, 1991

8- DIN 1048 Part 1, December 1978 edition.

9- DIN 1048 Part 5, June 1991 edition. 